\title{
PERCEPÇÃO DOS DISCENTES DO ENSINO MÉDIO DA CIDADE DE CAMPOS DOS GOYTACAZES/RJ SOBRE QUESTÕES AMBIENTAIS
}

\author{
Cristiane Barros CRESPO ${ }^{1}$, Kíssila da Conceição RIBEIRO ${ }^{1 *}$, Rui Manuel Pinto DANTIER ${ }^{1}$ \& Milton ERTHAL \\ JUNIOR $^{1,2}$
}

1 Instituto Federal de Educação, Ciência e Tecnologia Fluminense. Campos dos Goytacazes, Rio de Janeiro, Brasil. 2 Universidade Candido Mendes. Campos dos Goytacazes, Rio de Janeiro, Brasil.

*Autor para correspondência: kribeiro@iff.edu.br

DOI: http://dx.doi.org/10.18571/acbm.126

\section{RESUMO}

Este trabalho tem o objetivo de avaliar o conhecimento e a prática em Educação Ambiental (EA) dos discentes de escolas privadas e públicas (estaduais e federais) do ensino médio da cidade de Campos dos Goytacazes, RJ. A partir de um questionário contendo sete perguntas, foram analisados 2585 discentes vinculados a $1^{\mathrm{a}}$ e $3^{\mathrm{a}}$ série de doze escolas da cidade. Na análise dos dados foram usadas média, erro padrão, teste t de student e análise de variância. Na opinião dos discentes a EA não é abordada com frequência nas disciplinas, apesar de considerarem que seus professores são, na maioria dos casos, aptos para ensinar o tema. Os alunos das escolas privadas obtiveram as melhores notas (75\% de acertos) e um avanço significativo de conhecimento em EA entre a $1^{\mathrm{a}}$ e a $3^{\mathrm{a}}$ série. O mesmo não ocorre nas escolas públicas, demonstrando uma estagnação de conhecimento nesta área ao longo do ensino médio. Os alunos das escolas estaduais acertaram, em média, $73 \%$ das questões, enquanto que na rede federal de ensino estes acertaram $67 \%$. O avanço no conhecimento ambiental ao longo da permanência do discente no ensino médio deveria ser melhorado nas escolas, principalmente nas públicas, considerando o aspecto genérico das perguntas do questionário. $\mathrm{O}$ fato preocupante foi observar que nas escolas públicas não há avanço de conhecimento nesta área entre a $1^{\mathrm{a}}$ e a $3^{\mathrm{a}}$ série. Portanto, é necessária uma abordagem mais efetiva nas práticas desenvolvidas no ambiente escolar relativas as questões ambientais.

Palavras chave: Educação Ambiental; Gestão Ambiental; Sustentabilidade.

\begin{abstract}
This work aims to evaluate the knowledge and practice in Environmental Education (EA) of high school students in private and public (state and federal) schools in the city of Campos dos Goytacazes / RJ. From a questionnaire containing seven questions, we analyzed 2,585 students enrolled at the first and third year of high school of twelve schools in the city. Mean, standard error, student $t$ test and analysis of variance were used in the data analysis. In the students' opinion, EA is not often approached in the disciplines, although they consider that their teachers are, in most cases, apt to teach the subject. Students in private schools obtained the best grades (75\% of correct answers) and a significant improvement in EA knowledge between 1st and 3rd years of high school. The same does not occur in public schools, demonstrating a stagnation of knowledge in this area throughout high school. The students of the state schools answered, on average, $73 \%$ of the questions correctly, while in the federal schools they got $67 \%$ right. The advance of the student's environmental knowledge throughout high school should be improved, especially in public schools, considering the generic
\end{abstract}




\section{Biomedica Brasiliensia}

ISSN: $2236-0867$

aspect of the questions in the questionnaire. The worrying fact was to observe that in public schools there is no improvement regards to the knowledge in this area between 1st and 3rd years. Therefore, a more effective approach to practices developed in the school regarding environmental issues is needed.

Keywords: Environmental Education; Environmental Management; Sustainability.

\section{Introdução}

Atualmente, os problemas ambientais estão cada vez mais visíveis em decorrência das ações causadas pelos homens ao longo de sua existência, alguns autores afirmam que está instalada uma crise ambiental, que surgiu há muito tempo e vem se intensificando a cada dia (AVILA E LINGNAU, 2015). Há décadas são feitas conferências internacionais para tentar solucionar essa crise, no intuito de consolidar o Desenvolvimento Sustentável na busca de uma sociedade sustentável, equilibrando o crescimento econômico com a preservação do meio ambiente e a qualidade de vida (STANFORD, 2010). Effting (2007) afirma que a espécie humana tem dificuldade em estabelecer o seu limite de crescimento e, de conviver harmonicamente com outras espécies e com o planeta. Este mesmo autor esclarece que é necessário sensibiliza-los para que sejam responsáveis e conscientes em suas ações.

Para promover o Desenvolvimento Sustentável é imprescindível a cooperação humana, e as práticas devem ser geradas por políticas governamentais, empresas privadas, organizações e sociedade (ABRAMOVAY, 2010).

Para Araújo (2015) é através da vida escolar que é possível conseguir o equilíbrio do meio ambiente, ou seja, a Educação Ambiental é um instrumento de proteção na qual a Constituição colocou como dever do Poder Público a garantia dessa educação, com o intuito da população reconhecer sua importância e contribuir para preservação ecológica.

População consciente e participativa pode resultar em mudanças significativas no que tange ao consumo exacerbado imposto pelo atual sistema capitalista, que ultrapassa a capacidade de abastecimento renovado pelos recursos naturais.

A escola ganha destaque, tem o dever de preparar os alunos não só para a carreira, mas também para a vida (PERRENOUD, 2011). Nesse sentido, a educação deve estar voltada para a construção de valores educativos e morais, é a propulsora da mudança de comportamento e padrões. Conforme a Lei 9.795 a Educação Ambiental (EA) deve estar presente de forma articulada em todos os níveis e modalidades, tomando-se um componente essencial e permanente na educação (BRASIL,1999).

Nos Parâmetros Curriculares Nacionais (PCN's) consta que além da escola há outros componentes que podem agregar nesta tarefa, sendo a família com os padrões de comportamento e as informações disponibilizadas pela mídia, pois estas também exercem influências. Estes ensinamentos advindos fora da escola, no qual o aluno tende a reproduzir, torna muita das vezes um desafio para os educadores (BRASIL, 2002).

Udompong e Wongwanich (2013) destacam que a sociedade atual exige uma mudança dinâmica que requer uma ligação entre as competências essenciais e a complexidade da vida, essa combinação pode ter frutos do trabalho desempenhado nas escolas que é formar cidadãos aptos a pensar, serem criativos, analíticos, críticos, que adquiram conhecimentos, que tenham capacidade de resolver os problemas e tomarem decisões assertivas.

Apesar da importância do tema algumas escolas não trabalham a Educação Ambiental como uma única disciplina, ou seja, ela é discutida dentre as outras, mas se isso não for acompanhado pode haver algum deslize e comprometer os trabalhos de conscientização ambiental. É preciso que haja um trabalho de educação ambiental mais intenso, abrangente e contínuo, a maneira como se é trabalhada 
precisa ser acompanhada e se necessário reavaliada, pois os alunos devem se apropriar desse conhecimento e estar sensibilizados a ponto de agirem de forma ambientalmente correta (MONTEIRO, 2006).

Com isso, este artigo propõe avaliar as questões ambientais na percepção da $1^{\mathrm{a}}$ e $3^{\mathrm{a}}$ série do ensino médio de algumas escolas. Analisar e verificar se o processo de aprendizagem e desempenho acadêmico dos estudantes foram capazes de sensibiliza-los a ponto de fazê-los agir de forma ambientalmente correta.

\section{Material e Métodos}

O presente trabalho foi desenvolvido através de aplicação de questionários (surveys) aos discentes da $1^{\mathrm{a}}$ e $3^{\mathrm{a}}$ série do ensino médio de 12 escolas (pública e privada) do município de Campos dos Goytacazes/RJ. Para a elaboração do questionário foi realizado um levantamento bibliográfico, partindo das análises dos artigos de periódicos das bases de dados disponíveis no portal da CAPES, ISI, Web of Knoledge e também de artigos apresentados em congressos relevantes e dissertações submetidas em universidades que discutem o tema educação ambiental. Foram utilizadas como palavras chave: Ensino brasileiro (Brazilian education), Educação ambiental (Environmental education), Questionários (Questionnaires), Métodos estatísticos (Statistical methods) e Resíduos sólidos (Solid waste), que geraram um grupo de referências utilizadas como apoio para elaboração deste trabalho.

Com base nesses dados foram construídos os questionários para serem aplicados aos discentes, que continham questões ambientais fechadas e quantitativas. Os discentes são da $1^{\mathrm{a}}$ e $3^{\mathrm{a}}$ série do ensino médio, sendo duas escolas da rede federal, cinco escolas da rede privada e cinco escolas da rede estadual, totalizando em doze escolas que foram escolhidas aleatoriamente dentro da gama de instituições de ensino existentes no município de Campos dos Goytacazes. Para o cálculo do número amostral foi levado em consideração a população a ser analisada com um erro de 5\% através da Fórmula 1 (GIL,1988). Com base neste cálculo foi estimado o número de questionários a ser aplicado em cada uma das escolas selecionadas, considerando os discentes da $1^{\mathrm{a}}$ e $3^{\mathrm{a}}$ série do ensino médio, disponível na Tabela 1.

$$
n=\frac{\sigma^{2} \cdot p \cdot q \cdot N}{e^{2}(N-1)+\sigma^{2} \cdot p \cdot q}
$$

[Fórmula 1]

Sendo, $\mathrm{n}$ - tamanho da amostra; $\sigma$ - nível de confiança; $\mathrm{p}$ - percentagem com a qual o fenômeno se verifica; q - percentagem complementar (100-p); N - tamanho da população; e- erro máximo permitido. 
Tabela 1. Escolas pesquisadas, número total de discentes e número de discentes entrevistados, considerando-se um erro amostral de $5 \%$.

\begin{tabular}{|c|c|c|c|c|c|c|c|}
\hline \multirow{2}{*}{ Categoria } & \multirow{2}{*}{ Escola } & \multicolumn{2}{|c|}{$1^{\mathrm{a}}$ série } & \multirow{2}{*}{$\%$} & \multicolumn{2}{|c|}{$3^{\mathrm{a}}$ série } & \multirow{2}{*}{$\%$} \\
\hline & & População & Amostra & & População & Amostra & \\
\hline \multirow{3}{*}{$\begin{array}{l}\text { Pública } \\
\text { Federal }\end{array}$} & A & 320 & 175 & 54,7 & 332 & 179 & 53,9 \\
\hline & B & 85 & 70 & 82,4 & 28 & 27 & 96,4 \\
\hline & Total & 405 & 245 & 60,5 & 360 & 206 & 57,2 \\
\hline \multirow{6}{*}{ Privada } & $\mathrm{C}$ & 130 & 98 & 75,4 & 121 & 93 & 76,9 \\
\hline & $\mathrm{D}$ & 126 & 96 & 76,2 & 102 & 81 & 79,4 \\
\hline & $\mathrm{E}$ & 86 & 71 & 82,6 & 45 & 41 & 91,1 \\
\hline & $\mathrm{F}$ & 92 & 75 & 81,5 & 78 & 65 & 83,3 \\
\hline & $\mathrm{G}$ & 102 & 81 & 79,4 & 98 & 79 & 80,6 \\
\hline & Total & 536 & 421 & 78,5 & 444 & 359 & 80,9 \\
\hline \multirow{6}{*}{$\begin{array}{l}\text { Pública } \\
\text { estadual }\end{array}$} & $\mathrm{H}$ & 275 & 161 & 58,5 & 175 & 121 & 69,1 \\
\hline & I & 262 & 157 & 59,9 & 138 & 102 & 73,9 \\
\hline & $\mathrm{J}$ & 248 & 151 & 60,9 & 142 & 104 & 73,2 \\
\hline & $\mathrm{K}$ & 273 & 160 & 58,6 & 168 & 118 & 70,2 \\
\hline & $\mathrm{L}$ & 264 & 157 & 59,5 & 180 & 123 & 68,3 \\
\hline & Total & 1322 & 786 & 59,5 & 803 & 568 & 70,7 \\
\hline Total & & 2263 & 1452 & 64,2 & 1607 & 1133 & 70,5 \\
\hline
\end{tabular}

No questionário aplicado constavam sete questões, sendo perguntas de opiniões gerais e com relação a percepção do entrevistado. O mesmo foi estruturado com sete afirmações fechadas, cada uma com possibilidade de marcação de uma única alternativa.

Nas questões de percepção, foi utilizada a escala de Likert (1932), sendo disponibilizadas cinco alternativas em gradação quanto aos graus de concordância e uma alternativa de abstenção. As afirmações tinham um enunciado positivo (benefícios), desta forma, a concordância representa uma resposta favorável. Para que fosse possível uma interpretação estatística dos dados, foram atribuídos valores às alternativas.

Para o nível de Concordância foi utilizada a seguinte escala: 1 Discordo Totalmente, 2 Discordo parcialmente, 3 Nem discordo nem concordo, 4 Concordo parcialmente, 5 Concordo totalmente e $\mathrm{N}$ para Não sei ou não quero opinar. Já para o nível de Frequência atribuída a cada critério, foram usados: 1 Nunca, 2 Quase nunca, 3 Às vezes, 4 Quase sempre, 5 Sempre e N para Não sei ou não quero opinar.

Os dados obtidos pelos questionários foram analisados estatisticamente utilizando o software SAEG (Sistema para Análises Estatísticas e Genéticas), versão 9.1, sendo calculadas as médias do grau de concordância nas questões de percepção discente sobre aspectos ambientais. Foram calculadas e comparadas as médias por série $\left(1^{\mathrm{a}}\right.$ e $\left.3^{\mathrm{a}}\right)$, por categoria (privada, pública federal e pública estadual) e, para cada categoria, foram calculadas e comparadas as médias por série. Nas comparações entre séries, foi utilizado o teste $\mathrm{t}$ de Student com dados não pareados e, nas comparações entre categorias, foram utilizados a análise de variância e o teste de Tukey, sendo adotado nível de 5\% de significância.

\section{Resultados}

Na Figura 1 é possível constatar que, na opinião dos discentes, a temática sobre EA não é abordada com frequência nas disciplinas. Em média, os discentes "concordam parcialmente" que seus professores estão aptos para lecionar sobre EA. A preocupação com a higiene do ambiente escolar 
está acima do ponto mediano (entre "sempre" e "quase sempre”), porém, através de observação pessoal, pode-se perceber que esta preocupação não gera ação efetiva, haja visto as condições do ambiente escolar logo após o uso por parte dos discentes. Quando questionados sobre sua participação em iniciativas para o uso racional dos recursos hídricos a média obtida foi "às vezes", porém quando questionados sobre a preocupação com o desperdício e a redução do recurso a média obtida está entre "quase sempre" e "sempre" demonstrando afirmações contraditórias, a preocupação sobre a problemática envolvendo a questão hídrica não gera ações efetivas para o gerenciamento deste recurso. As iniciativas dos discentes quanto ao uso racional de energia estão abaixo da média, mas, por outro lado, eles se posicionaram entre "concordam parcialmente" e "Não concordo nem discordo" quanto a serem cidadãos ecologicamente corretos.

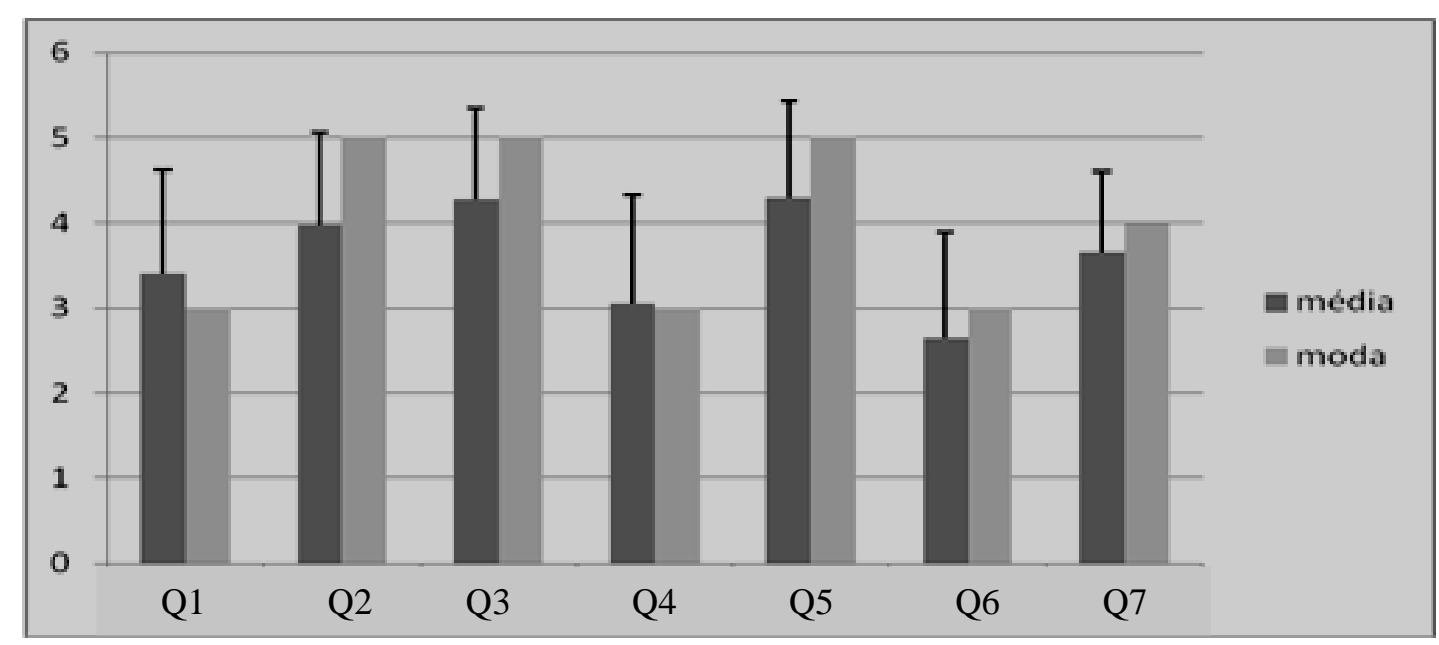

Figura 1: Respostas da população total de discentes entrevistados sobre questões ambientais Onde: Q1. Frequência de abordagem da educação ambiental nas disciplinas regulares; Q2. Aptidão docente para inclusão de conteúdos sobre educação ambiental em suas disciplinas; Q3. Preocupação com a higiene do ambiente escolar; Q4. Participação em iniciativas para redução de consumo hídrico; Q5. Preocupação com desperdício de recurso hídrico; Q6. Participação em iniciativas para redução do consumo de energia;

Q7. Cidadão ecologicamente correto; as questões Q2 e Q7 apresentam padrão de resposta “Concordo totalmente a discordo totalmente". As questões Q1, Q3, Q4, Q5, e Q6 apresentam padrão de resposta "sempre a nunca".

$\mathrm{Na}$ Figura 2 consta que somente os discentes da rede privada consideram que a abordagem sobre o tema EA aumenta ao longo do ensino médio, os discentes das demais redes tem a percepção de que a abordagem do tema reduz ao longo do ensino médio. Na análise geral, na rede federal conta que os discentes consideram haver menor frequência na abordagem do tema. De acordo com os discentes entrevistados matriculados na $1^{\text {a }}$ série do ensino médio, na rede estadual ocorre a maior frequência de abordagem do tema e na percepção dos discentes matriculados na $3^{\mathrm{a}}$ série do ensino médio, na rede privada ocorre a maior frequência de abordagem do tema, ficando entre "as vezes" e "quase sempre". 


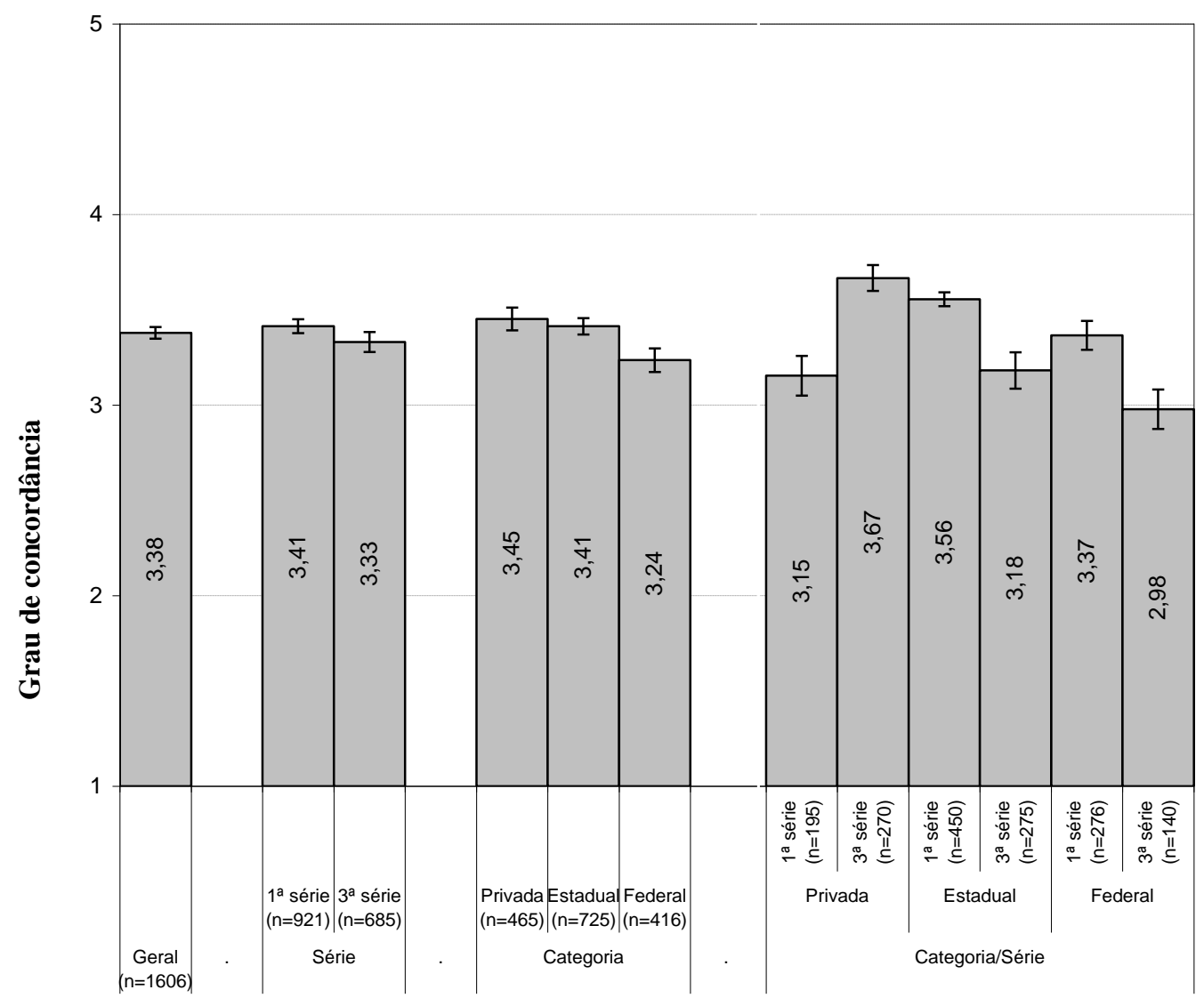

Figura 2: Percepção dos discentes do ensino médio sobre sua concordância quanto ao item "Frequência de abordagem da educação ambiental nas disciplinas regulares".

Os discentes da rede privada apresentam o maior nível de concordância sobre a aptidão dos professores na abordagem do tema EA, conforme é demonstrado pela Figura 3. Estes relataram que como a EA não é disciplina regular no currículo escolar, em geral, os docentes abordam de maneira muito informal o tema. Os discentes consideram que a aptidão dos docentes é menor nas séries mais avançadas do ensino médio. 


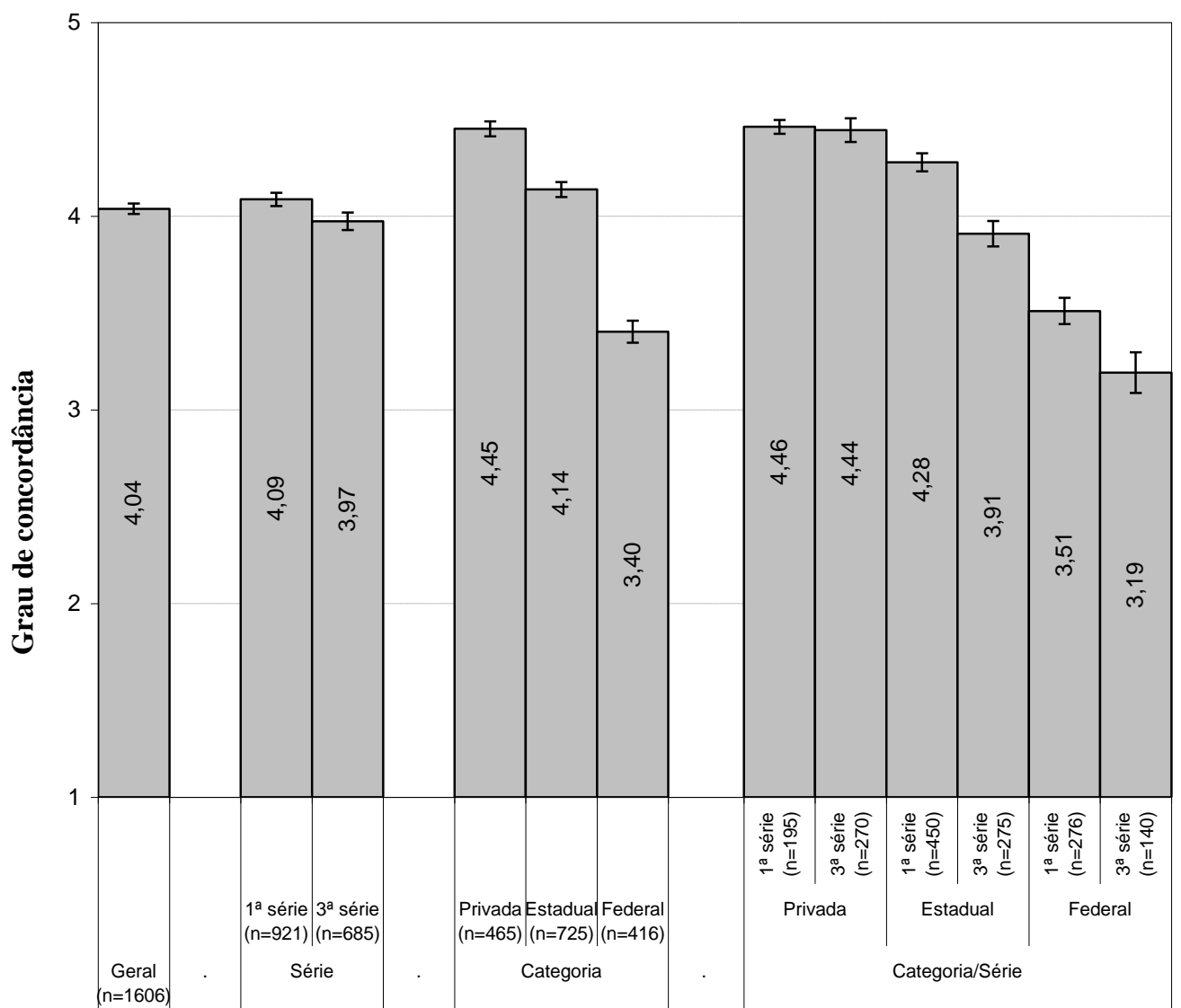

Figura 3: Média de frequência sobre o item "Aptidão docente para inclusão de conteúdos sobre educação ambiental em suas disciplinas" na percepção dos discentes do ensino médio regular.

Na Figura 4, observa-se que a preocupação com a higiene do ambiente escolar apresenta, em todas as redes, de forma crescente ao longo do ensino médio, com médias de frequência entre "quase sempre" e "sempre", com excessão dos discentes da $1^{a}$ série da rede estadual que obtiveram a menor frequência, com média entre "as vezes" e "quase sempre", sendo estes os menos preocupados com a higiene do ambiente escolar. 


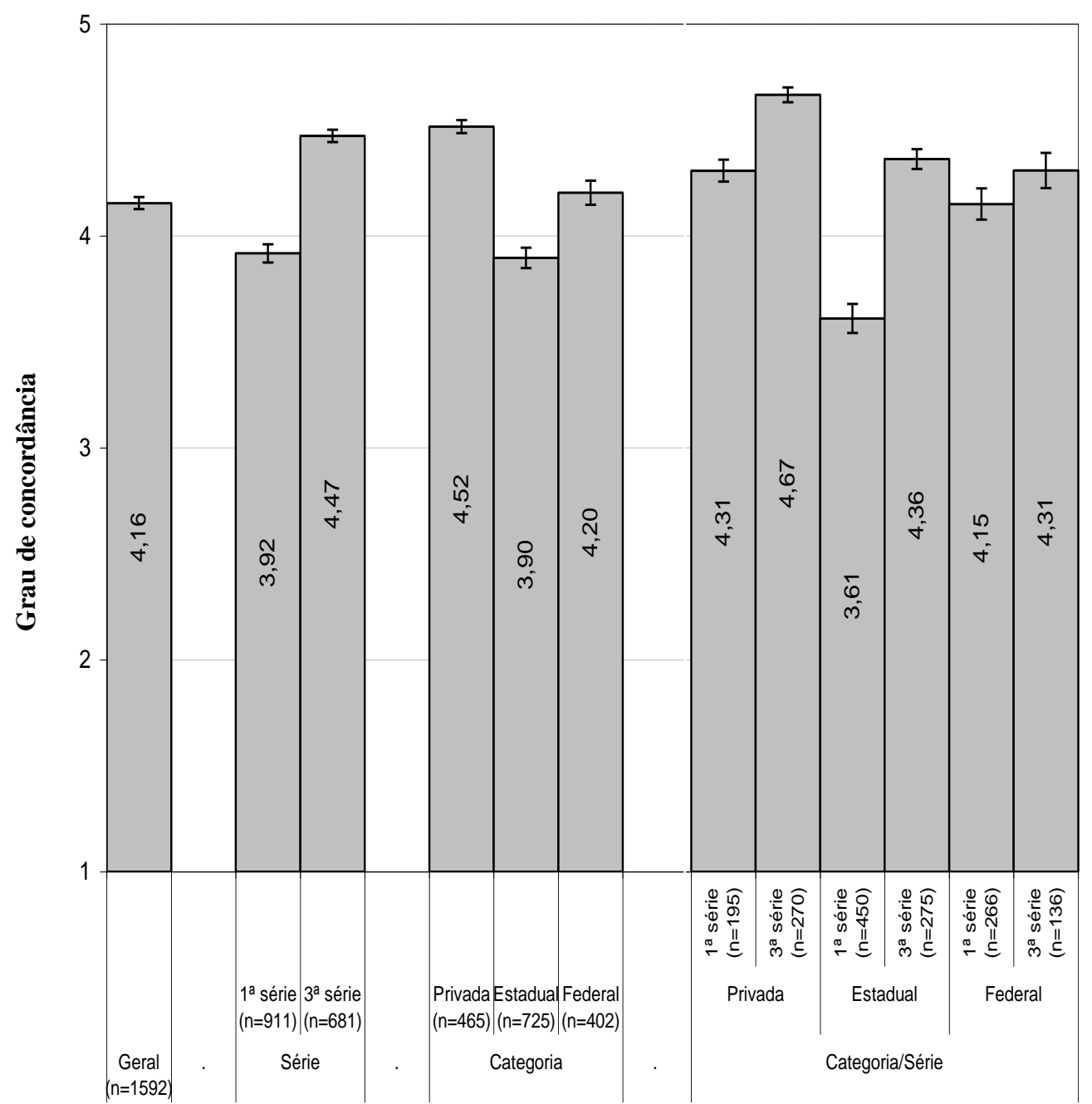

Figura 4: Média de concordância sobre o item "Preocupação com a higiene do ambiente escolar" na percepção dos discentes do ensino médio regular.

A Figura 5 apresenta que as iniciativas para redução do consumo hídrico de acordo com os discentes da rede privada e estadual decrescem ao longo do ensino médio, com exceção da rede federal. Os discentes que apresentam a maior frequência de participação neste tema são da rede estadual, apresentando média de frequência "as vezes" na percepção dos discentes entrevistados de ambas as séries. 


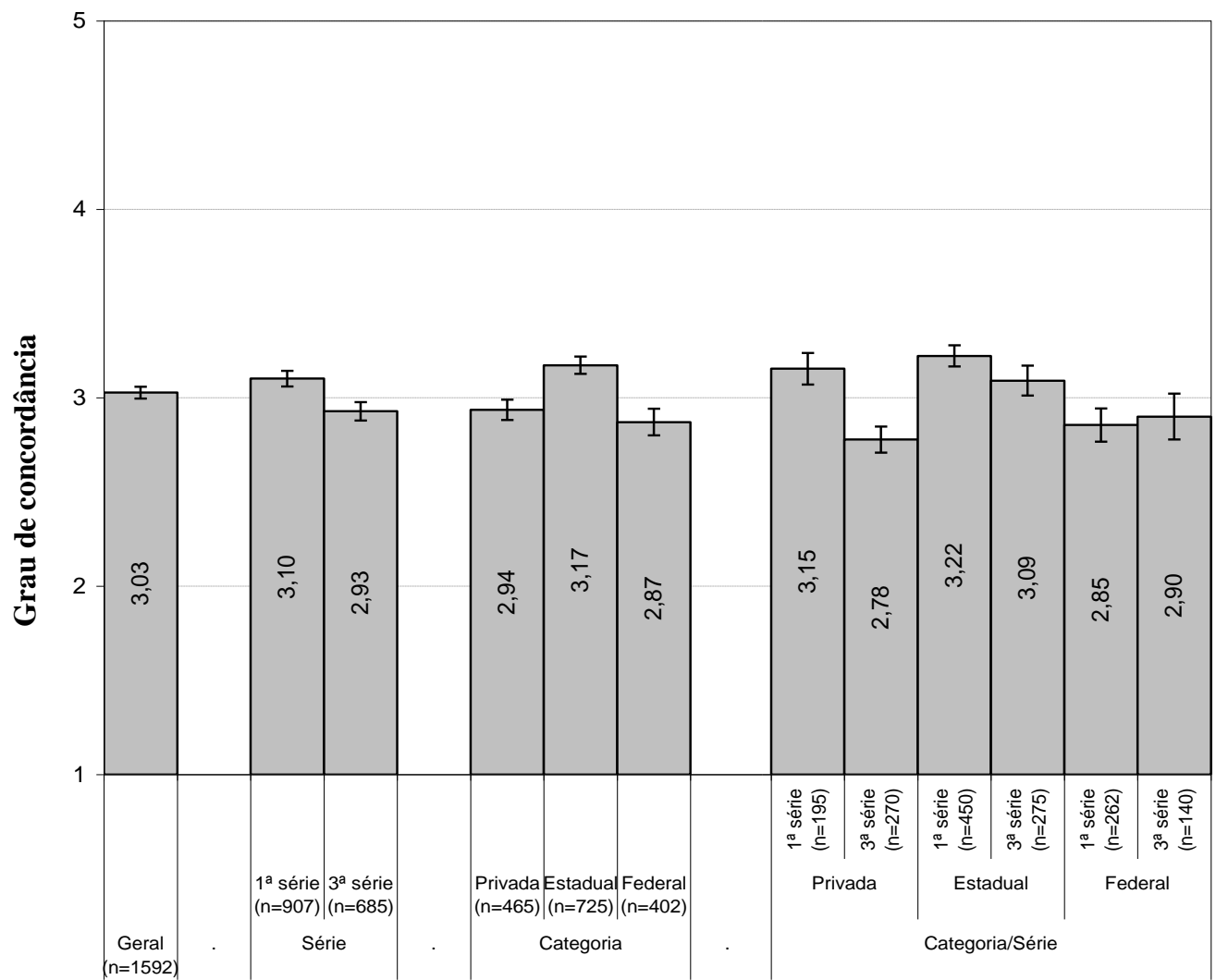

Figura 5: Média de concordância sobre o item "Participação em iniciativas para redução de consumo hídrico" na percepção dos discentes do ensino médio regular.

Observa-se na Figura 6, que os discentes da rede federal são os que apresentam a menor média de preocupação com o desperdício e a redução dos recursos hídricos, na comparação geral e entre as séries entrevistadas. Ao longo do ensino médio a rede privada é a que demonstra maior crescimento na média de preocupação observada. 


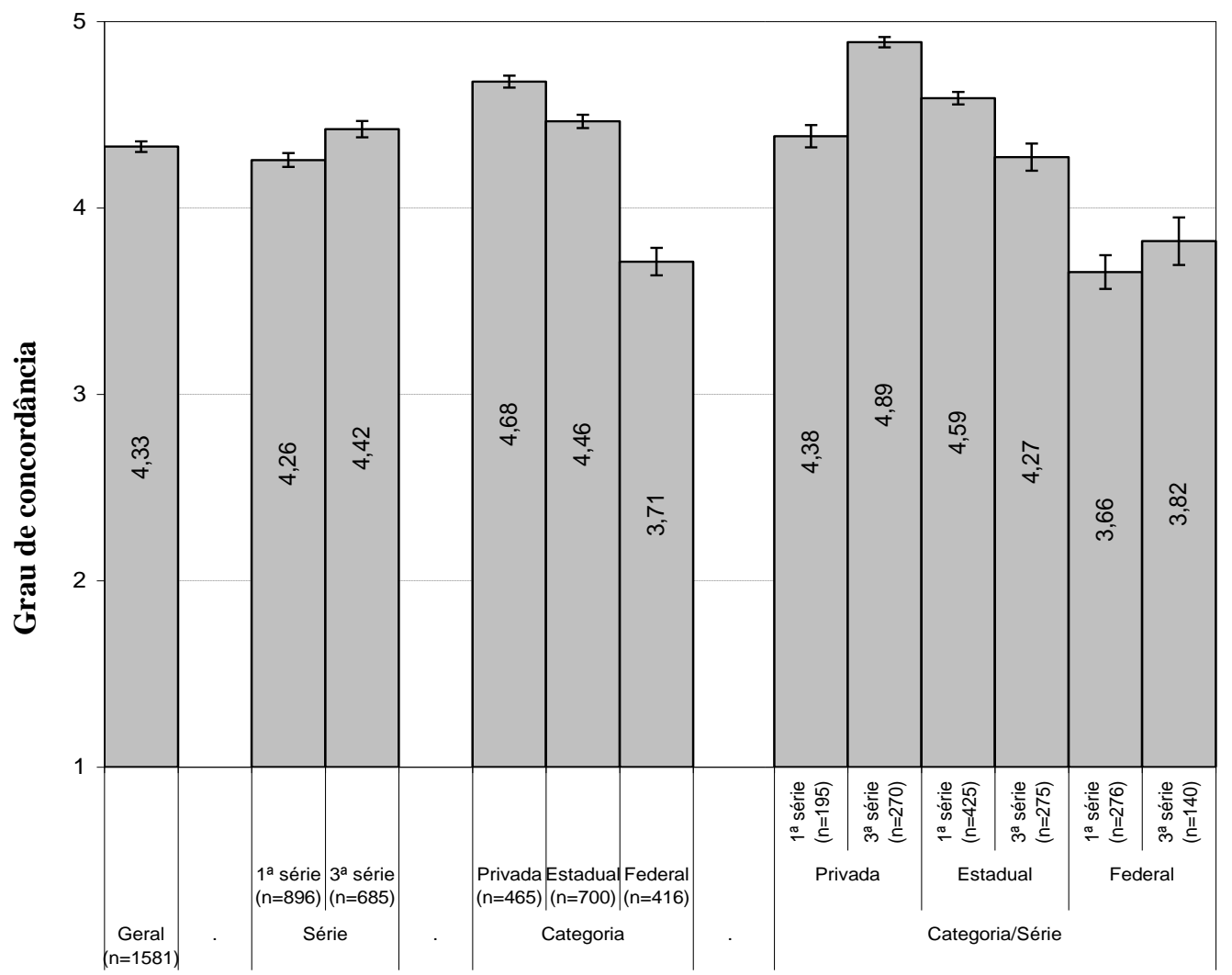

Figura 2: Média de concordância sobre o item "Preocupação com desperdício de recurso hídrico" na percepção dos discentes do ensino médio regular.

A figura 7 retrata que a preocupação com a redução do consumo de energia, ao longo do ensino médio e independente das redes de ensino, apresentaram médias de frequência entre "quase nunca" e "as vezes", sendo a maior média demonstrada pelos discentes da rede estadual com um discreto aumento na média de preocupação entre a $1^{\mathrm{a}}$ e $3^{\mathrm{a}}$ série. 


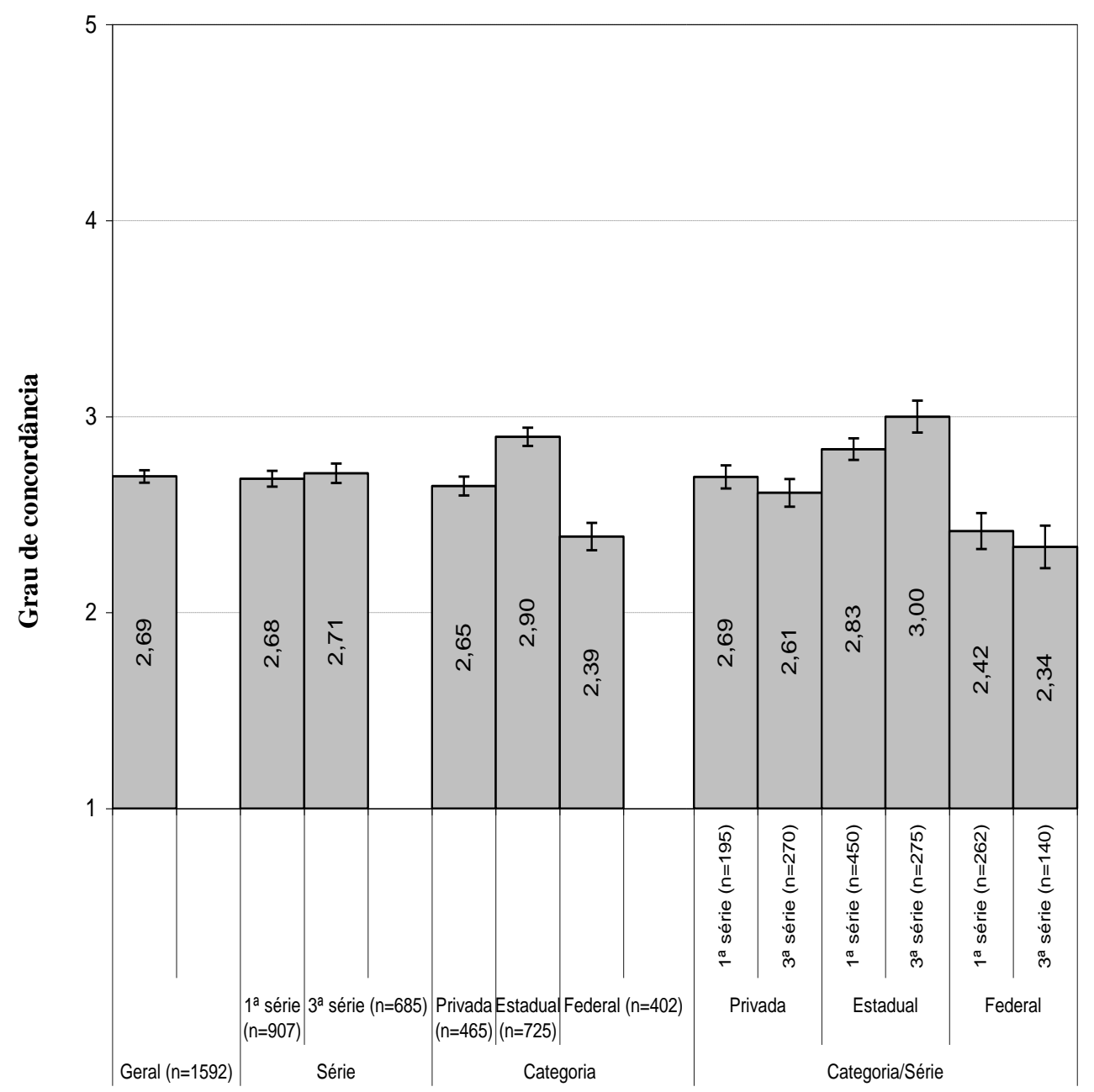

Figura 3: Média de concordância sobre o item "Participação em iniciativas para redução do consumo de energia" na percepção dos discentes do ensino médio regular.

Observa-se na Figura 8, que os discentes se consideram cidadãos ecologicamente correto com frequência de "as vezes" e "quase sempre" independente da rede a da série analisada, na qual a rede privada obteve a maior média e com discreto crescimento ao longo do ensino médio. 


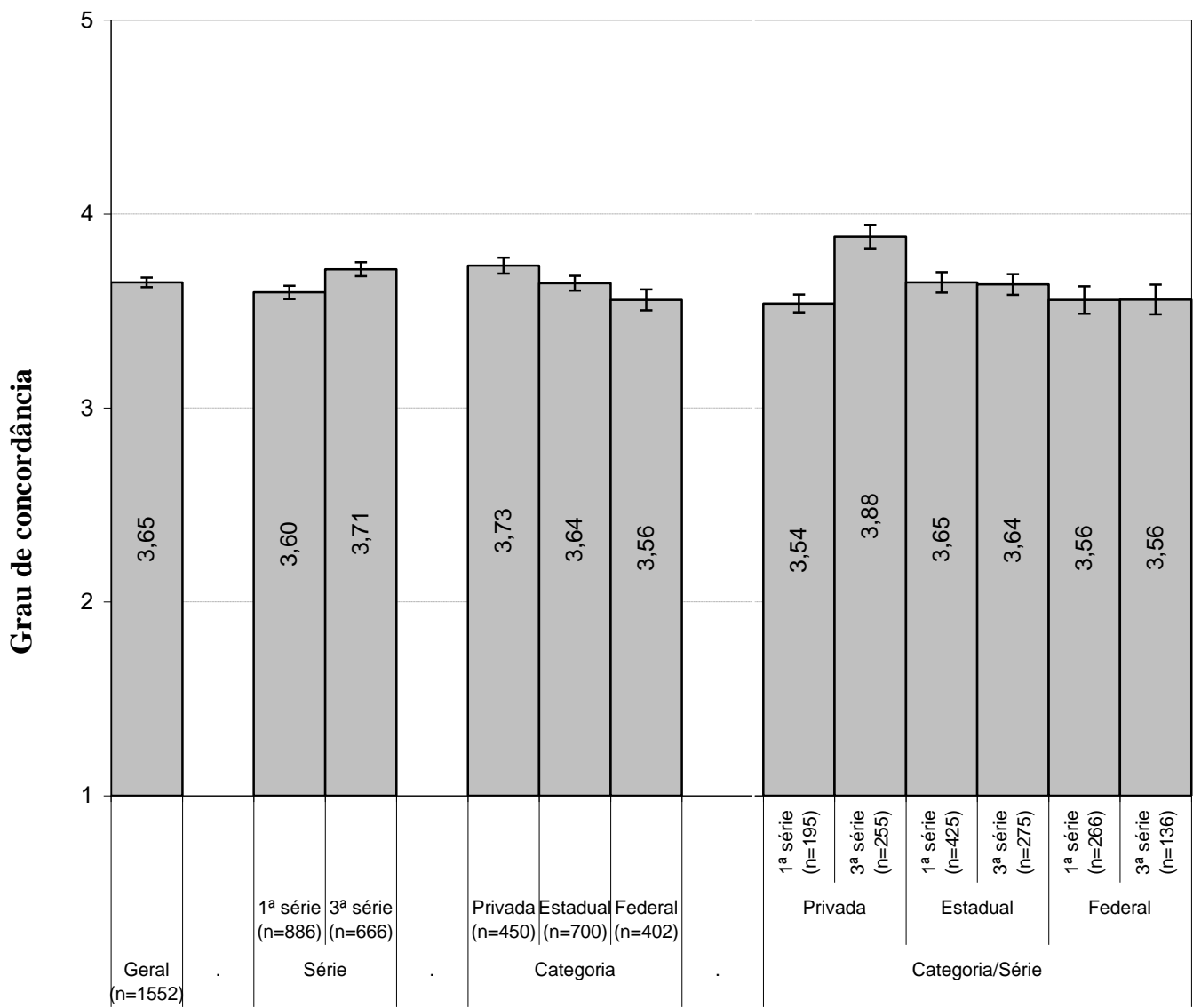

Figura 8: Média de concordância sobre o item "Cidadão ecologicamente correto" na percepção dos discentes do ensino médio regular.

\section{Discussão}

$\mathrm{Na}$ Tabela 2 pode-se observar uma visão geral das médias obtidas nas séries e categorias de ensino, considerando a percepção dos discentes para as sete questões de conhecimento geral sobre EA. Apesar dos alunos da terceira série perceberem uma diminuição na frequência de abordagem (Q1) da EA, e na aptidão dos professores para incluir conteúdos sobre EA em suas disciplinas (Q2), em geral, a terceira série, independente da rede de ensino do aluno, tem diferença significativa com relação aos alunos da primeiro série, indicando que os alunos concluintes evoluem durante o período escolar, aumentando sua percepção com relação as questões ambientais.

Com relação a categoria escolar, há diferença significativa entre as redes de ensino, obedecendo a seguinte ordem decrescente de percepção - privada, estadual e federal respectivamente.

Sampaio e Guimarães (2009) analisaram a eficiência das escolas públicas e privadas no Brasil, o resultado mostrou que o ensino privado obteve eficiência máxima, mas a rede federal também obteve destaque, apresentando eficiência equiparada com o ensino privado. Para o ensino público estadual, a eficiência do ensino ficou pouco acima da eficiência média, prejudicando mais os alunos com melhores notas. Observa-se que apesar de se avaliar a educação, porém com objetivos e parâmetros diferentes, a rede privada se destacou, por outro lado houve uma inversão com relação a esfera federal e estadual. 
Comparando categoria/série, os dados mostram que na rede privada, houve uma diminuição na frequência na Q2, Q4, Q6, porém na média, aumentou o grau de concordância, ocorrendo diferença significativa entre a primeira e a terceira série. Na esfera estadual ocorreu um aumento da frequência na Q3 e Q6, as demais questões apresentaram uma diminuição, apesar da diferença não ser estatisticamente significativa. Ao analisar a rede federal percebe-se que na Q3, Q4, Q5, ocorreu um aumento, porém na média, da primeira para a terceira série diminuiu, contudo não houve diferença significativa.

Há uma divergência comparando a percepção dos discentes sobre "preocupação com o desperdício/redução dos recursos hídricos" (Q5) e a "participação em iniciativas para redução do consumo dos recursos hídricos" (Q4), os alunos do $3^{\circ}$ ano da rede particular são os mais preocupados, com média de frequência entre "quase sempre" e "sempre", porém são os que tem menor participação, com média de frequência entre "quase nunca" e "as vezes". Mas, na média por categoria a rede estadual é a que mais participa tanto na questão da redução de consumo hidríco quanto no consumo de energia, isso é resultado de que nessa rede estão presentes indivíduos com faixa etária maior do que nas demais redes, alguns já estão inseridos no mercado de trabalho e também são responsáveis pelo sustento familiar, o que justifica o resultado obtido, uma vez que esta questão está associada, geralmente, com a economia financeira no lar, situação também destacada por Vilar et al (2008).

Mesmo que a prática não tenha sido destaque na rede privada, eles são os que mais se consideram ecologicamente correto, uma incoenrência entre a teoria e a prática.

Tabela 2: Médias de percepção discente sobre questões ambientais que envolvem conhecimento geral.

\begin{tabular}{|c|c|c|c|c|c|c|c|c|c|c|c|}
\hline \multirow{3}{*}{ Perguntas } & \multirow{2}{*}{\multicolumn{2}{|c|}{ Série }} & \multirow{2}{*}{\multicolumn{3}{|c|}{ Categoria }} & \multicolumn{6}{|c|}{ Categoria/Série } \\
\hline & & & & & & \multicolumn{2}{|c|}{ Privada } & \multicolumn{2}{|c|}{ Estadual } & \multicolumn{2}{|c|}{ Federal } \\
\hline & $1^{a}$ & $3^{\mathbf{a}}$ & Privada & Estadual & Federal & $\mathbf{1}^{\mathrm{a}}$ & $3^{a}$ & $\mathbf{1}^{\mathrm{a}}$ & $3^{\mathrm{a}}$ & $\mathbf{1}^{\mathrm{a}}$ & $3^{\mathrm{a}}$ \\
\hline Q1 & 3,41 & 3,33 & 3,45 & 3,41 & 3,24 & 3,15 & 3,67 & 3,56 & 3,18 & 3,37 & 2,98 \\
\hline Q2 & 4,09 & 3,97 & 4,45 & 4,14 & 3,40 & 4,46 & 4,44 & 4,28 & 3,91 & 3,51 & 3,19 \\
\hline Q3 & 3,92 & 4,47 & 4,52 & 3,90 & 4,20 & 4,31 & 4,67 & 3,61 & 4,36 & 4,15 & 4,31 \\
\hline Q4 & 3,10 & 2,93 & 2,94 & 3,17 & 2,87 & 3,15 & 2,78 & 3,22 & 3,09 & 2,85 & 2,90 \\
\hline Q5 & 4,26 & 4,42 & 4,68 & 4,46 & 3,71 & 4,38 & 4,89 & 4,59 & 4,27 & 3,66 & 3,82 \\
\hline Q6 & 2,68 & 2,71 & 2,65 & 2,90 & 2,39 & 2,69 & 2,61 & 2,83 & 3,00 & 2,42 & 2,34 \\
\hline Q7 & 3,60 & 3,71 & 3,73 & 3,64 & 3,56 & 3,54 & 3,88 & 3,65 & 3,64 & 3,56 & 3,56 \\
\hline Média* & $3,58 \mathrm{~b}$ & $3,65 a$ & 3,77A & $3,66 \mathrm{~B}$ & $3,34 \mathrm{C}$ & $3,67 b$ & 3,85a & $3,68 a$ & $3,64 a$ & 3,36a & 3,30a \\
\hline
\end{tabular}

Legenda: Q1. Frequência de abordagem da educação ambiental nas disciplinas regulares; Q2. Aptidão docente para inclusão de conteúdos sobre educação ambiental em suas disciplinas; Q3. Preocupação com a higiene do ambiente escolar; Q4. Participação em iniciativas para redução de consumo hídrico; Q5. Preocupação com desperdício de recurso hídrico; Q6. Participação em iniciativas para redução do consumo de energia; Q7. Cidadão ecologicamente correto. *Médias seguidas da mesma letra minúsculas não diferem entre si pelo teste t, e médias de categorias seguidas da mesma letra maiúsculas não diferem entre si pelo teste de Tukey a 5\% de probabilidade.

Com base nesta análise e problemas, os profissionais da educação devem estar preparados para trazer e discutir estas questões no ambiente escolar. Para os autores Ferreira, Lopes e Morais (2006) a educação para a sustentabilidade tem que ter uma abordagem interdisciplinar, ou seja, um ensino holístico com o intuito de proporcionar uma aprendizagem profunda, preparando o aluno para resolver 


\section{ACTA

os problemas do mundo real, desenvolver habilidades e competências fora da instituição, e mais importante que o conhecimento é promover ações práticas de sustentabilidade.

Schwartzman (2005) destaca que a educação é constituída com o envolvimento das pessoas professores, alunos, funcionários das escolas, famílias e sociedade. A escola tem um papel fundamental, mas é a articulação entre os atores que proporciona os avanços. A mudança tem certo grau de complexidade, contudo geram conflitos, antagonismos e alteração na zona de conforto, que infelizmente não é possível esperar, continuar negando a natureza, faz urgir uma remodelação da sociedade com adoção de estratégias convertidas ao desenvolvimento sustentável.

\section{Conclusão}

O principal objetivo desta pesquisa foi analisar as questões ambientais na percepção dos discentes da $1^{\mathrm{a}}$ e $3^{\mathrm{a}}$ série do ensino médio de escolas da rede federal, estadual e privada do município de Campos dos Goytacazes. Verificar se o processo de aprendizagem e desempenho acadêmico dos estudantes foram capazes de sensibiliza-los a ponto de fazê-los agir de forma ambientalmente correta. Além disso, se houve avanço na percepção do conhecimento ambiental durante a permanência do discente na escola e se existe diferença no conhecimento ambiental entre os discentes das diferentes redes que oferecem formação de nível médio.

Através das respostas dos discentes foi possível observar que eles consideram que a temática sobre Educação Ambiental é abordada "às vezes" nas disciplinas e seus professores "quase sempre" estão aptos a abordar o tema, mas o resultado apontou que os alunos não estão sensibilizados com ações ambientais mesmo quando apresentam consciência sobre os problemas ambientais.

Embora o que se espera é que ao longo do ensino médio o conhecimento sobre as questões ambientais aumente, o trabalho apresentou que isso só ocorreu na esfera privada, pois na esfera pública não houve aumento significativo, demonstrando que o tema não é abordado de forma eficiente junto aos discentes.

Por mais relevante que seja a educação ambiental, é necessário reorientar a educação para valores de sustentabilidade, tal como participação, integração e conscientização na formação de um cidadão ativo, crítico e participativo em todos os níveis de ensino, conforme as recomendações, diretrizes e planos de ação já estabelecidos pelas conferências em educação ambiental de Belgrado em 1975, Tbilisi em 1977, Moscou em 1987, ECO 92 em 1992 e Thessaloniki em 1997.

Assim, como proposta para as instituições de ensino analisadas pode-se citar a orientação e fomenta aos docentes para uma abordagem mais frequente do tema ambiental em suas disciplinas, elaboração de eventos, atividades práticas, palestras, promover campanhas, debates, feiras e projetos na área ambiental tratando conhecimentos mais específicos, contribuindo na formação de jovens e futuros adultos conscientes (VILLAR et al, 2008). Portanto, há vários desafios conceituais e metodológicos, o processo pedagógico tem que ser transformador, no qual o indivíduo seja capaz de modificar suas atitudes em prol da coletividade.

Para Araújo (2015), a conscientização ambiental é capaz de transformar a sociedade na busca da preservação do meio ambiente, caso contrário colocam em risco a qualidade e a sobrevivência dos recursos naturais, dos seres vivos e principalmente da vida humana.

\section{Referências}

ABRAMOVAY, A. K. A relação escola-comunidade e a conservação ambiental. Monografia. Universidade Federal da Paraíba, João Pessoa, 2010. 
ARAÚJO, K. de L. Consumo, meio ambiente e sustentabilidade: um olhar sobre o saber ambiental segundo Leff. In: CUNHA, Belinda Pereira da et al (Org.). OS SABERES AMBIENTAIS, SUSTENTABILIDADE E OLHAR JURÍDICO: visitando a obra de Enrique Leff. Caxias do Sul: Educs, 2015. p. 271-309.

AVILA, A. M.; LINGNAU, R. Ensino de biologia e educação ambiental. Revista Monografias Ambientais, v. 14, n. 2, p. 137-150, 2015.

BRASIL. Lei ordinária n. 9795/99, de 28 de abril de 1999. Dispõe sobre a educação ambiental, institui a política nacional de Educação Ambiental e dá outras providências. Diário Oficial da República Federativa do Brasil, 28 abr. 1999: 1. col. 1.

. Ministério da Educação. Parâmetros Curriculares Nacionais , Ensino Médio Orientações Educacionais Complementares aos Parâmetros Curriculares Nacionais. Ciências da Natureza, Matemáticas e suas Tecnologias. Brasília. MEC/SEMTEC, 2002.

EFFTING, T.R. Educação ambiental nas escolas públicas: Realidade e desafios. Paraná, 2007.

FERREIRA, A. J. D.; LOPES, M. A. R.; MORAIS, J. P. F. Environmental management and audit schemes implementation as an educational tool for sustainability. Journal of Cleaner Production, v. 14, n. 9, p. 973-982, 2006.

GIL, A. C. Técnicas de pesquisa em economia. São Paulo: Atlas, 1988. 180p

MONTEIRO. G.D. Educação Ambiental - Princípios e práticas. São Paulo, 2006.

PERRENOUD, P. Quand l'école pretend preparer à la vie - Développer des compétences ou enseigner d'autres savoirs. ESF Éditeur, Paris, 2011.

SAMPAIO, B.; GUIMARÃES, J. Diferenças de eficiência entre ensino público e privado no Brasil. Revista de Economia Aplicada, São Paulo, v. 13, n. 1, p. 45-68, jan.-mar.2009.

SCHWARTMAN, S. Os desafios da educação no Brasil. In: SCHWARTMAN, S.; BROCK, C. Os desafios da educação no Brasil. Rio de Janeiro: Nova Fronteira, 2005.

STAFFORD, S. P. Intellectual virtues in environmental virtue ethics. Environmental Ethics, v. 32, n. 4, p. 339-352, 2010.

UDOMPONG, L.; WONGWANICH, S. Diagnosis of the scientific literacy characteristics of primary students. Procedia-Social and Behavioral Sciences, v. 116, p. 5091-5096, 2014.

VILLAR, L. M. et al. A percepção ambiental entre os habitantes da região noroeste do estado do Rio de Janeiro. Escola Anna Nery Revista de Enfermagem, v. 12, n. 2, p. 285-290, 2008. 